\title{
Do Psychiatric Out-patients take their Drugs?
}

\author{
D. R. C. WILLCOX,* M.C.PATH. ; R. GILLAN, $\dagger$ M.R.C.P., D.P.M. ; E. H. HARE, $\ddagger$ M.D.
}

Brit. med. F., 1965, 2, 790-792

It is common clinical experience that there are patients who do not take the drugs prescribed for them. Less is known of the frequency with which this occurs, but a number of studies have indicated that the failure rate may be surprisingly high-up to $50 \%$ (Benstead and Theobald, 1952 ; Haler, 1952; Mohler et al., 1955 ; Simpson, 1956 ; Dixon et al., 1957 ; Luntz and Austin, 1960).

The present study was undertaken to determine the proportion of psychiatric out-patients who do not take their drugs, and to examine some factors possibly associated with this.

\section{Procedure and Methods}

The patients included in this study were attending psychiatric out-patient clinics at the Maudsley Hospital-either a clinic for first attendance and reattendance or a clinic at which patients are followed up after discharge from the hospital. Any of these patients for whom chlorpromazine and/or imipramine was prescribed were accepted for this study. Clinical and psychometric data collected for each patient included age, sex, diag-

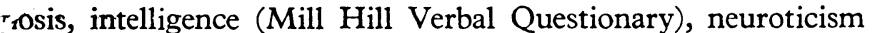
(Cornell Medical Index), whether the patient was living with the spouse, the type of drug, the presence of side-effects, and the patient's reply to inquiry whether he was taking tablets as prescribed.

A specimen of urine was collected from each patient at a regular out-patient attendance and tested to ascertain whether the drug was being taken. All patients had been prescribed their drug at least seven days before testing, but this interval was usually between two and four weeks. Many patients were tested on two or more occasions. The specimens of urine were collected without preservative; they were refrigerated on arrival at the laboratory and examined within a few days by the following methods.

\section{Estimation of Amphetamine-like Substances (A.L.S.)}

The method is slightly modified from that of Connell (1958), which was based on that of Brodie et al. (1947). A benzene extract of the alkalinized urine is made, and the amount of methyl-orange binding with the basic material in the benzene extract is estimated colorimetrically after removal to an acidaqueous phase. The method is thus non-specific, estimating, in terms of the standard used, any basic organic substance which is both soluble in benzene and capable of coupling with methylorange under the test conditions. When allowance is made for a normal urine content any excess can be attributed confidently to the presence of such a drug. This allowance is based on previous experience with normal subjects and patients known not to be taking reacting drugs.

For routine screening purposes the upper limit of " normal amines" has been placed at $200 \mu \mathrm{g} . / 100 \mathrm{ml}$. Drugs may, however, be detected by chromatography in urines having a level of total amphetamine-like substances in the upper part

- Consultant Pathologist, the Bethlem Royal and the Maudsley Hospital. t Senior Psychiatric Registrar, the Bethlem Royal and the Maudsley Hospital.

$\ddagger$ Consultant Psychiatrist, the Bethlem Royal and the Maudsley Hospital. of the normal range. The method estimates in the range of $20-1,000 \mu \mathrm{g} . / 100 \mathrm{ml}$. with an accuracy of plus or minus $12 \%$. It should be added that these values are of amphetamine-like substances, are in fact amphetamine equivalents, each reacting drug being assessed against an amphetamine standard. The relation between these values and micrograms of the actual drug concerned varies from drug to drug and is not always a simple molecular ratio. This has, however, been the standard practice throughout the investigation, and the point is important only if these values should be compared with others quoted for different methods of estimation.

\section{Chromatography}

The urine is extracted with benzene as in the method above. The extract is evaporated to dryness and the residue taken up in a small volume of benzene so that a suitable aliquot representing 10-20 $\mu \mathrm{g}$. of the estimated amphetamine-like substance can be applied to the paper. Whatman No. 2 is used, the chromatogram being developed during an eight-hour ascending run with butanol-water-acetic acid (12-5-3). Chlorpromazine and imipramine give rather high and close $R_{f}$ 's 86-88 and 90-93, but are readily distinguished in addition by staining reactions. A platinic-iodide reagent stains both substances with a slightly different blue colour with different rates of fading. Chlorpromazine stains pink with a ferricchloride reagent, and imipramine blue-green with potassium chromate in sulphuric acid. In pure solutions as little as $1 \mu \mathrm{g}$. can be identified, but $2-3 \mu \mathrm{g}$. is minimal in urine extracts.

\section{Criteria}

Although the method for estimating amphetamine-like substances has been in use for some years, and information has been collected of a variety of drugs reacting, additional information was sought concerning the variation in urinary levels throughout the day for various doses of chlorpromazine and imipramine, and also the period of excretion following their withdrawal. These points were studied in a number of in-patients, the results being summarized in Table $I$.

It is clear from these findings and the previous comments on the methods that several criteria of failure to take the drugs

\begin{tabular}{|c|c|c|c|}
\hline Drug & $\begin{array}{l}\text { Dose } \\
\text { (mg. t.d.s.) }\end{array}$ & $\begin{array}{l}\text { Range of Urinary A.L.S. Values } \\
\text { during Regular Therapy }\end{array}$ & $\begin{array}{c}\text { Period of } \\
\text { Excretion } \\
\text { Following } \\
\text { Withdrawal } \\
\end{array}$ \\
\hline \multirow{4}{*}{ Chlorpromazine \{} & 25 & \multirow{3}{*}{$\begin{array}{l}\text { Often within normal range,* } \\
\text { excess up to } 200 \mu \mathrm{g} . / 100 \mathrm{ml} \text {. } \\
\text { Occasional top normal values, }{ }^{*} \\
\text { usually } 100-300 \mu \mathrm{g} . / 100 \mathrm{ml} \text {. } \\
\text { excess } \\
>500 \mu \mathrm{g} . / 100 \mathrm{ml} \text {. excess in all } \\
\text { specimens }\end{array}$} & 24 hours \\
\hline & 50 & & $"$ \\
\hline & 75 & & Not tested \\
\hline & 100 & " $\quad " \quad " \quad "$ & " \\
\hline \multirow[b]{2}{*}{ Imipramine } & 25 & $\begin{array}{l}\text { Slight excess up to } 200 \mu \mathrm{g} . / \\
100 \mathrm{ml} \text {. }\end{array}$ & 1-3 days \\
\hline & $\begin{array}{l}50 \\
75\end{array}$ & $\begin{array}{l}200-300 \mu \mathrm{g} . / 100 \mathrm{ml} \text {. excess } \\
400->1,000 \mu \mathrm{g} . / 100 \mathrm{ml} . \text { excess }\end{array}$ & $\begin{array}{l}3-4, ", \\
\text { Not tested }\end{array}$ \\
\hline
\end{tabular}

- Drug detected chromatographically in all specimens. 
as prescribed can be used. Thus a negative chromatogram is an absolute indication of failure. However, with this criterion alone patients who may have omitted to take imipramine for as long as two or three days would not be assessed as failing to take the drug. The finding of no excess of amphetaminelike substances is the next criterion. This, however, cannot be applied to patients on $25 \mathrm{mg}$. t.d.s. of chlorpromazine, since such patients may be expected to have some high normal values. Finally, the actual level of an excess of amphetamine-like substances can be compared with the expected range for that dosage, and where major discrepancies exist the patient may fairly be classed as failing to take the drug as prescribed. This should be applied only to chlorpromazine dosage over $50 \mathrm{mg}$. t.d.s., and to imipramine of $50 \mathrm{mg}$. t.d.s. or more.

\section{Results}

This study comprised 125 patients who were prescribed chlorpromazine and/or imipramine. Urinary A.L.S. were estimated for all patients, and chromatograms for the recognition of the drugs were prepared for 112 patients. Table II shows the results of classifying all the patients by the criteria discussed above. The proportion of failures varies from $33 \%$ to $59 \%$. Assessment by negative chromatogram is clearly an underestimate, whereas assessment by expected values should be near the true proportion but may include transient failures, as in a patient who may have omitted only his midday dose on the day of his out-patient appointment. In what follows we have used only the first two criteria-that is, negative chromatography, and no excess of amphetamine-like substances.

TABLE II.-Patients Failing to Take Drugs as Prescribed: Use of
Various Criteria

To investigate the consistency of their drug-taking behaviour 58 patients were tested on two occasions (Table III). More than $80 \%$ of these patients have results consistently positive or negative. Each drug subgroup shows the same trend. Twelve of these 58 patients, moreover, were tested three to five times, and their results (Table IV) show only one patient (No. 8) with a single negative, the remainder being consistent throughout, or showing more than one negative result.

A total of 70 patients were prescribed imipramine alone, all of whom had their urinary A.L.S. estimated, and 60 were tested

TABle III.-Consistency of Results from Patients Tested on Troo

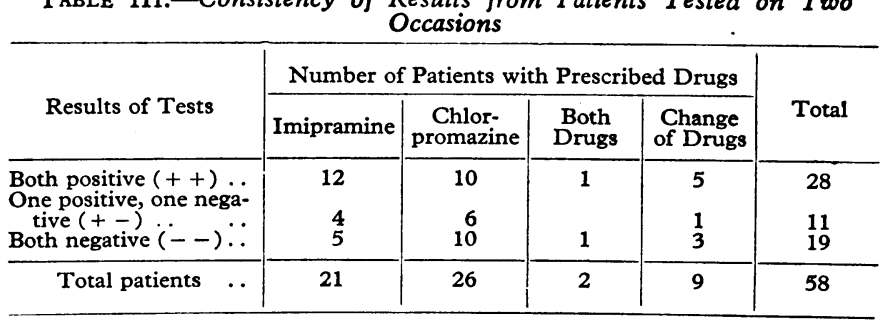

TABLE IV.-Results from Patients Tested on 3-5 Occasions

\begin{tabular}{c|c|c|c}
\hline Patient & Result & Patient & Result \\
\hline 1 & - \pm- & 7 & +++- \\
2 & - \pm- & 8 & ++- \\
3 & + \pm- & 9 & +++ \\
4 & + \pm+ & 10 & +++ \\
5 & 11 & +++++++++++ \\
\hline
\end{tabular}

chromatographically. Fifty-two patients were prescribed chlorpromazine alone, all having urinary A.L.S. estimated, and 48 were tested by chromatograph. When these results are considered separately for male and female patients, two separate criteria of failure being used (Table V), there is no indication of any sex difference in drug-taking. The underestimate by chromatography is demonstrated for the imipramine patients, but the two assessments for the chlorpromazine patients are very similar. The second criterion, which has been used for the remaining data, still shows a higher rate of failure for chlorpromazine than for imipramine, but the difference is not great.

\begin{tabular}{|c|c|c|c|c|c|c|}
\hline \multirow{2}{*}{$\begin{array}{l}\text { Criteria of Failure } \\
\text { and Drug Prescribed }\end{array}$} & \multicolumn{2}{|c|}{ Males } & \multicolumn{2}{|c|}{ Females } & \multicolumn{2}{|c|}{ Total Patients } \\
\hline & $\begin{array}{l}\text { No. } \\
\text { Tested }\end{array}$ & $\underset{\text { Rate }}{\text { Failure }}$ & Nosted & $\underset{\text { Rate }}{\text { Failure }}$ & $\begin{array}{l}\text { No. } \\
\text { Tested }\end{array}$ & $\begin{array}{l}\text { Pailure } \\
\text { Rate }\end{array}$ \\
\hline $\begin{array}{l}\text { egative chromato- } \\
\text { graphy: } \\
\text { Chlorpromazine } \\
\text { Imipramine.. }\end{array}$ & $\begin{array}{l}26 \\
24 \\
\end{array}$ & $\begin{array}{l}54 \% \\
33 \% \\
\end{array}$ & $\begin{array}{l}22 \\
36 \\
\end{array}$ & $\begin{array}{l}59 \% \\
22 \% \\
\end{array}$ & $\begin{array}{l}48 \\
60 \\
\end{array}$ & $\begin{array}{l}56 \% \\
27 \% \\
\end{array}$ \\
\hline $\begin{array}{l}\text { o excess of A.L.S.: } \\
\text { Chlorpromazine } \\
\text { Imipramine .. }\end{array}$ & $\begin{array}{l}26 \\
30\end{array}$ & $\begin{array}{l}54 \% \\
47 \%\end{array}$ & $\begin{array}{l}26 \\
40\end{array}$ & $\begin{array}{l}54 \% \\
40 \%\end{array}$ & $\begin{array}{l}52 \\
70\end{array}$ & $\begin{array}{l}54 \% \\
43 \%\end{array}$ \\
\hline
\end{tabular}

The drug failures were next examined in relation to diagnosis (Table VI). Three main groups emerge. The largest group, depressed patients treated with imipramine, show a failure rate (44\%) differing little from that for the whole series (48\%). Depressed patients prescribed chlorpromazine, however, show a much higher failure rate, and a similar-sized group of schizophrenics also prescribed chlorpromazine had a rather lower rate.

\begin{tabular}{|c|c|c|c|c|c|c|}
\hline \multirow{2}{*}{\multicolumn{5}{|c|}{ Drug Prescribed and Diagnosis }} & \multicolumn{2}{|c|}{ Patients } \\
\hline & & & & & \multirow{2}{*}{$\begin{array}{c}\text { Number Tested } \\
20 \\
22 \\
10\end{array}$} & \multirow{2}{*}{$\begin{array}{c}\text { Failure Rate } \\
70 \% \\
32 \% \\
70 \%\end{array}$} \\
\hline $\begin{array}{c}\text { Chlorpromazine p } \\
\text { Depression } \\
\text { Schizophrenia } \\
\text { Other } \quad . . \\
\end{array}$ & $\begin{array}{l}\text { presc } \\
\ldots \\
\ldots \\
\ldots\end{array}$ & $\begin{array}{l}\text { ed: } \\
\therefore \\
\because\end{array}$ & $\begin{array}{l}\cdots \\
\therefore\end{array}$ & $\begin{array}{l}. \\
\therefore \\
\end{array}$ & & \\
\hline $\begin{array}{l}\text { Imipramine presc } \\
\text { Depression } \\
\text { Schizophrenia } \\
\text { Other } \quad .\end{array}$ & $\begin{array}{c}\text { cribe } \\
\ldots \\
\ldots\end{array}$ & $\because$. & $\begin{array}{l}. \\
\therefore\end{array}$ & $\begin{array}{l}\because \\
\therefore\end{array}$ & $\begin{array}{r}59 \\
4 \\
7\end{array}$ & $\begin{array}{c}44 \% \\
(25 \%) \\
(57 \%)\end{array}$ \\
\hline
\end{tabular}

Approximately $50 \%$ of imipramine patients and $20 \%$ of chlorpromazine patients had symptoms thought to be sideeffects of the drugs. It is clear from Table VII that the failure rate is not appreciably influenced by the presence of side-effects. The chlorpromazine patients without side-effects show a rather higher rate. This is due to the influence of the depressed group referred to above as having the highest failure rate. Only four of this group complained of side-effects, and three of these were taking their drugs satisfactorily.

TABLB VII.-Failure to Take Drugs : Relation to Side-effects

\begin{tabular}{|c|c|c|c|c|c|}
\hline \multirow{2}{*}{\multicolumn{4}{|c|}{ Drug and Effects }} & \multicolumn{2}{|c|}{ Patients } \\
\hline & & & & Number Tested & Failure Rate \\
\hline $\begin{array}{l}\text { Imipramine: } \\
\text { With side-effects } \\
\text { Without side-effects } \\
\end{array}$ & $\because$ & $\because$. & $\because$. & $\begin{array}{l}33 \\
37 \\
\end{array}$ & $\begin{array}{l}45 \% \\
43 \%\end{array}$ \\
\hline $\begin{array}{l}\text { Chlorpromazine: } \\
\text { With side-effects } \\
\text { Without side-effects }\end{array}$ & 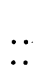 & 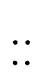 & $\because$ & $\begin{array}{l}11 \\
41\end{array}$ & $\begin{array}{l}45 \% \\
56 \%\end{array}$ \\
\hline
\end{tabular}

The remaining findings can be briefly summarized. Age, intelligence, and neuroticism showed no correlation with failure to take drugs. Of men living alone $52 \%$ failed to take drugs, compared with $35 \%$ of men living with their wives. Two corresponding groups of women showed no difference in drugtaking. Thirty-one per cent. of patients who stated that they were taking their tablets as directed were assessed as failing to do so. 


\section{Discussion}

A patient who is prescribed drugs may take none of them, or he may take them for a short time and then stop, or he may take them irregularly. The answer to the question, "Is this patient taking his drugs ?" will depend on the criterion used. A verbal inquiry can compass some or all of the various ways in which a patient may not take his drugs. Urine tests for drug excretion give restricted answers, but have the advantage of objectivity, an advantage of particular importance in this context. In the present study a negative urine test for amphetamine-like substances (including a negative chromatogram where low dosage of chlorpromazine made the first test unsatisfactory) indicates that the patient had not been taking the drug during the previous 24 hours (or longer for imipramine patients according to dose). This might mean only a temporary and isolated lapse in taking his tablets, though sometimes of significant duration. The findings, however, that a second urine test usually gave the same result as the initial one, and that in multiple tests the results from any patient were usually consistent, suggest that a single negative test may generally be taken to indicate that the patient had not been taking his drug at all, or not with any regularity, for many days or weeks.

The use of this criterion has demonstrated a failure rate of $48 \%$ in the whole series. This may be compared with failure rates of over $20 \%$ (Haler, 1962) and $33-40 \%$ (Benstead and Theobald, 1952) in women attending antenatal clinics and prescribed ferrous sulphate. In these studies the failures were apparently assessed as a result of inquiry. In two groups of tuberculous out-patients prescribed P.A.S. urine tests indicated failure rates of $50 \%$ (Dixon et al., 1957) and 30-40\% (Luntz and Austin, 1960), higher values being related to length of treatment in the latter study. Two reports on schizophrenic out-patients (Parkes et al., 1962 ; Renton et al., 1963) quote rates of $44-46 \%$ obtained by inquiry. Joyce (1962), investigating patients' co-operation in a trial of drugs for rheumatoid arthritis, classified approximately $50 \%$ of out-patients as " obedient" on the results of counts of tablets remaining at each interview. He also used a phenol-red marker in the tablets for half the patients, and obtained only 38 of 108 expected positive urine tests ; but the significance of this is difficult to judge in the absence of details of the excretion time of the marker. $\mathrm{He}$ demonstrated that different conclusions regarding the effects of the drug might be drawn when allowance was made for the varied intake. From these various authors came suggestions that factors relating to failure to take drugs include length of treatment, presence of side-effects, a feeling of well-being, and lack of supervision.

Our findings do little to elucidate the reasons why patients omit their drugs. Age, sex, intelligence, and side-effects had no apparent influence. The fact that men living alone defaulted more often than those living with their wives suggests a beneficial influence of supervision. The failure rate varied with diagnosis and with the drug, but our observations suggest no simple explanation.

While the causes may remain obscure, the fact seems to be established that a very large proportion of psychiatric outpatients fail to take their drugs. Some consequences of the extent of this failure may be mentioned. There is a considerable waste of drugs and money. The accumulation of unused drugs in the homes of patients is a source of danger. Drug trials in which there is no reliable check on whether the patients are taking the drugs as prescribed can be seriously misleading.

\section{Summary}

Tests were made of 125 psychiatric out-patients to ascertain whether they were taking the chlorpromazine or imipramine that had been prescribed.

Criteria of failure to take the drugs were based on information of the drugs' excretion by in-patients, and included both a quantitative test and sensitive and specific chromatographic tests.

The results indicate that the failure rate for the whole series was $48 \%$. The rate for patients prescribed chlorpromazine was slightly higher than that for those prescribed imipramine, and was also higher for depressives than for schizophrenics within the chlorpromazine group.

Failure rate was not associated with age, sex, intelligence, or drug side-effects.

The results are discussed and attention is drawn to the implied waste of drugs, the danger of unused drugs in the home, and the possible unreliability of out-patient drug trials.

\section{REFERENCES}

Benstead, N., and Theobuld, G. W. (1952). Brit. med. F., 1, 407. Brodie, B. B., Udenfriend, S., and Dill, W. (1947). F. biol. Chem., 168,

Connell, P. H. (1958). Amphetamine Psychosis. Maudsley Monograph, No. 5. Chapman and Hall, London.

Dixon, W. M., Stradling, P., and Wootton, I. D. P. (1957). Lancet, $2,871$.

Haler, D. (1952). Brit. med. F., 2, 1241.

Joyce, C. R. B. (1962). f. chron. Dis., 15, 1025.

Luntz, G. R. W. N., and Austin, R. (1960). Brit. med. F., 1, 1679. Mohler, D. N., Wallin, D. G., and Dreyfus, E. G. (1955). New Engl. 7. Med., 252, 1116.

Parkes, C. M., Brown, G. W., and Monck, E. M. (1962). Brit. med. ₹.,

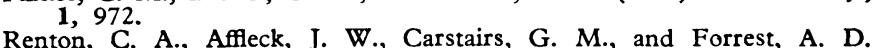
(1963) Acta psychiat scand. 39, 548.

Simpson, J. M. (1956). Tubercle (Lond.), 37, 333.
Coarctation of the lower thoracic aorta was reviewed by Bahnson, Cooley, and Sloan (1949), and Beattie, Cooke, Paul, and Orbison (1951) were the first to treat a case successfully by resection and the insertion of a homograft.

The following case is reported in view of the mode of presentation, the unique manner of progression at a youthful age, and the successful early treatment.

\section{Case Report}

A girl aged 7 years had first been referred to the Hallstrom Institute of Cardiology, Royal Prince Alfred Hospital, from the Royal Newcastle Hospital in July 1962, at the age of 5, when she complained of chest pain that had developed during skipping

\footnotetext{
* Department of Cardiothoracic Surgery, Royal Prince Alfred Hospital,
} Sydney, Australia. 